\title{
O VINHO NO BRASIL E SUA PRESENÇA NA LITERATURA
}

\author{
Zuzana Burianová
}

\begin{abstract}
After a short outline of the history of viticulture in Brazil, the article moves on to the topic of wine in Brazilian literature. It focuses on a particular book dedicated exlusively to this subject: the collection of texts entitled Histórias de Vinho, published in 1980 as a special edition on the occasion of the $50^{\text {th }}$ anniversary of the wine company Vinícola Rio Grandense. Through a thematic analysis of the texts in poetry and prose written by twenty-one authors, mostly from Rio Grande do Sul, the article draws attention to the rich variety of the ways this specific topic, generally not very frequent in literature, can be examined in texts that differ in terms of genres, style, perspective and tone.
\end{abstract}

Keywords: wine; Rio Grande do Sul; Brazilian literature; fiction; poetry.

Resumo: Depois de um breve esboço da história da vitivinicultura no Brasil, o artigo aborda o tema do vinho na literatura brasileira. Focaliza um livro concreto, dedicado exclusivamente a este assunto: a coletânea de textos intitulada Histórias de Vinho, publicada no ano de 1980 como edição especial em comemoração aos 50 anos da Vinícola Rio Grandense. Através de uma análise temática dos textos em poesia e prosa de vinte e um autores, na maior parte gaúchos, o artigo chama atenção à riqueza dos modos como este tema específico, em geral pouco frequente na literatura, pode ser tratado em textos de diferentes gêneros, estilos, perspectivas e tons.

Palavras-chave: vinho; Rio Grande do Sul; literatura brasileira; prosa; poesia.

A tradição vitivinícola no Brasil remonta ao século XVI, quando os primeiros colonos tentaram cultivar videiras no sudeste do país. No Rio Grande do Sul, hoje a principal região de produção de vinhos, foram os padres jesuítas que introduziram as primeiras castas, com o fim de obter vinho para as missas católicas. Foram seguidos por colonos alemães que trouxeram cultivares européias, mais tarde adotando também videiras de origem americana. Porém, o principal desenvolvimento das atividades vinícolas, na década 70 do séc. XIX, deveu-se à chegada dos imigrantes italianos que, munidos com uma vasta cultura de produção e consumo de vinhos, se fixaram sobretudo na região serrana, no nordeste do estado. A vitivinicultura brasileira aperfeiçou-se sobretudo nas duas últimas décadas. Hoje em dia o país, desde 1995 membro da OIV (Organização Internacional do Vinho), produz vinhos de boa qualidade, entre os quais se destacam os espumantes. Às principais regiões produtoras pertence, além da Serra Gaúcha do Rio Grande do Sul (com os centros de Bento Gonçalves, Caxias do Sul, Farroupilha, Antonio Prado, Flores da Cunha ou Garibaldi), ${ }^{1}$ também o Vale do São Francisco, situado entre Pernambuco

\footnotetext{
1 Duarte-Goés 1997: 39.
} 
e Bahia, que pode contar, como a única região vitivinícola do mundo, com duas colheitas por ano. Uma parte da produção nacional de vinhos provém também das regiões de São Paulo, Minas Gerais, Paraná e Santa Catarina. ${ }^{2}$

A história do vinho no Brasil é assim tão longa como a presença dos europeus em seu território. Aliás, foi já a expedição de Pedro Álvares Cabral que no momento da chegada ao Brasil, em 1500, carregava em suas treze caravelas uma grande quantidade de vinho para abastecimento dos marinheiros. A prova deste fato pode ser encontrada na Carta de Achamento, ${ }^{3}$ em que Pêro Vaz de Caminha, escrivão-mor da frota, informa o rei D. Manuel sobre o descobrimento da nova terra. Na descrição do primeiro contato dos portugueses com os nativos, ele capta a vã tentativa dos marinheiros de oferecer comidas e bebidas européias aos indígenas:

Deram-lhes ali de comer: pão e peixe cozido, confeitos, fartéis, mel e figos passados. Não quiseram comer quase nada daquilo; e, se alguma coisa provaram, logo a lançavam fora. Trouxeram-lhes vinho numa taça; mal lhe puseram a boca; não gostaram nada, nem quiseram mais. Trouxeram-lhe água em uma albarrada. Não beberam. Mal a tomaram na boca, que lavaram, e logo a lançaram fora. (Cit. em Moisés 1995: 14)

Apesar de que o motivo do vinho esteja presente já no primeiro documento literário do país, os textos das épocas seguintes não abundam em alusões a este néctar dos deuses. Uma pesquisa minuciosa ao longo da história da literatura nacional certamente revelaria, sobretudo nos textos dos autores sulistas, várias referências ao vinho. Este, porém, não é nosso objetivo. O que nos interessa é reparar nos diferentes modos como o vinho pode entrar na literatura, nas tonalidades com as quais pode ser tratado como tema ou motivo, nas associações que pode suscitar dentro do texto literário. Para isso nos servimos de um livro dedicado exclusivamente ao vinho: da coletânea de textos intitulada Histórias de Vinho, publicada como edição especial em comemoração aos 50 anos da Vinícola Rio Grandense, produtora dos vinhos Granja União. O livro contém textos em poesia e prosa de vinte e um autores, na maior parte gaúchos que, variando no estilo, tom e perspectiva, giram todos em torno do vinho. Devido às diferenças na abordagem do assunto entre os textos prosaicos e os poéticos, que partem já da natureza dos dois gêneros, decidimos analisá-los separadamente, tentando agrupá-los, dentro destas categorias genéricas, conforme as características temáticas que apresentam em comum.

\section{Textos de prosa}

Seria ingênuo esperar que as narrativas do livro falem sobre o vinho em si, ou seja, sobre suas qualidades, variedades, sabores ou aromas. Como nos adverte Armando Coelho Borges no texto introdutório, «O gosto do vinho», um bom vinho, tal como uma boa música, não se pode descrever. Só se pode beber, libertando emoções subjetivas e evocando sensações diferentes para cada um: «Na falta de palavras exatas deve-se preferir o silêncio. (...) ...o prazer de tomá-lo não tem, qualquer semelhança com a descrição mais poética ou exata que se possa fazer a seu respeito». (HV - Histórias de Vinho: 12) Os nove textos em prosa representam histórias, casos ou situações que abordam o tema indiretamente,

\footnotetext{
2 Ver, por exemplo, as seguintes fontes da internet: http://www.e-vinho.com.br.; http://www.vinhosdobrasil. com.br.; http:/ / www.academiadovinho.com.br.; http:/ / www.sitedovinhobrasileiro.com.br.

3 Carta a el-rei D. Manuel sobre o achamento do Brasil, escrita em 1500, ficou inédita até 1817, quando foi publicada pelo padre Manuel Aires do Casal na Corografia Brasílica, no Rio de Janeiro.
} 
falando antes sobre a relação do homem com o vinho e sobre as diferentes siginificações que este pode adquirir na vida humana.

Dois textos do conjunto discutem a origem do vinho, ambos apresentando uma explicação jocosa de como o vinho surgiu na terra. «O mundo (no) vinho em folha (ou versão retificada do Gênesis)», de Mário de Almeida Lima, vai até os tempos pré-históricos. Desenvolve a teoria de que o vinho, respetivamente o vinho tinto, é anterior ao homem, fazendo jus ao ser chamado de néctar divino, pois tem a origem realmente divina: «Deus, no sexto dia da criação, tendo sentido sede, não uma sede de água, mas de outro líguido ainda não imaginado, criou o vinho, e tendo-o bebido, viu que era bom». (HV: 90) Só depois de criar o vinho, Deus moldou do barro Adão, pela simples razão de ter alguém para compartilhar o prazer de beber. Deus é apresentado como um ser aborrecido com o tédio infinito no qual tem que viver, longe de ser infalível como o supõem os futuros sábios - «sublimes idiotas» (HV: 92-93), como os chama. Pelo contrário, ele comete erros como qualquer mortal, um dos maiores sendo o fato de ter criado o homem. É que este só abusa da bondade de seu «Chefe», pedindo-lhe primeiro para inventar o queijo e depois, já meio embriagado, a mulher para ter alguém igual a ele a seu lado. Assim, o vinho está presente também na origem da mulher e desempenha um papel importante ainda em outro momento crucial da história humana: quando Adão e Eva comem da maçã da sabedoria e envergonham-se da própria nudez, cobrem-se não com folhas de figueira, como consta no Gênesis, mas com folhas de parra.

O texto intitulado «Como nasceu o vinho», de Millôr Fernandes, tem uma explicação mais «terrestre» para a origem desta bebida: na época em que ainda não havia álcool, um homem meio idiota chamado Álvaro perdeu-se durante viagem de uma aldeia para outra, na Espanha, alimentando-se apenas com o caldo de uvas que levava no cantil e que, disposto ao sol, com o tempo começou a fermentar. Daí o nome desta bebida alcoólica que deu origem a todas as outras: vem do nome diminuto de seu «inventor»Alvinho.

Uma interessante reflexão sobre o papel não apenas do vinho, mas do álcool em geral na vida humana, é apresentada no texto «Por que bebemos tanto assim», de Paulo Mendes Campos. O autor inicia seu pensamento com uma advertência perante o perigo do álcool, visto como uma espada de dois gumes, como «um veneno mortal que consola e... degrada o homem» (HV: 145). Simultaneamente, porém, ele lembra também outra visão, mantida por exemplo pelo escritor inglês G. K. Chesterton, de que não é o álcool que degrada o homem mas o homem quem degrada o álcool. Segue-se uma análise dos motivos pelos quais o homem bebe, rematada com uma frase lapidar: «bebemos para empatar com o mundo». (HV: 146) O homem luta para acertar o passo com a realidade que está, contudo, sempre ganhando, e a bebida ajuda-o a fugir a si mesmo, a esquecer as frustrações e humilhações de sua existência. Esta idéia é ainda aprofundada por uma crítica social: além de nosso próprio destino estamos expostos a inúmeras tensões dentro de uma sociedade hieraquizada, «engenhosamente arquitetada para triturar as classes de baixo». (HV: 152) O espírito e o corpo do homem estão sempre em controvérsia, pois «o primeiro conhece exaustivamente a morte, enquanto o segundo é imortal, enquanto vive». (HV: 147) Ao longo de sua vida, o homem procura em vão resolver esta discrepância e, alimentado por sonhos, fantasias e ilusões, recorre à psicanálise, à ciência, à arte, ao amor... Ou ao álcool, porque a embriaguez por algum tempo diminui «a presença do espírito desesperado dentro do corpo, perfeitamente disposto a possuir os bens terres- 
tres e gozá-los». (HV: 147) ${ }^{4}$ Na visão de Campos, o homem precisa estar bêbado de qualquer mentira possível, oferecendo-lhe o álcool a via primária a este estado. A apologia da embriaguez é apoiada ainda por outra característica sua que é a dimensão religiosa. O homem bebe não apenas para afogar as mágoas do espírito, mas também para transcender a si mesmo, para se aproximar, em um momento epifânico, dos deuses. O autor lembra que a embriaguez, atingida através de um cogumelo especial, fazia parte dos antigos ritos religiosos, por exemplo na Grécia ou entre os indígenas mexicanos. Assim, no bar de hoje o homem sublima do mesmo modo como o fazia perante o altar de ontem.

A relação do vinho com os rituais religiosos é captada, embora de maneira mais leve, também no texto «O princípio e o fim», de Josué Guimarães. O vinho aqui está presente nos momentos limítrofes da vida humana, sendo consumido em grande quantidade por um padre nos ofícios de extrema-unção e batismo. Porém, por trás das passagens humorísticas que descrevem a bebedeira deste servidor de Deus, sentimos a crítica social da pobreza e das duras condições de vida dos campesinos. Está patente logo no início do texto, quando o padre lembra o corpo de um vinhateiro, assaltado no momento de levar ao banco o dinheiro que a duras penas tinha conseguido ganhar na produção do vinho. Nesta realidade, não é de surpreender que até um padre, às vezes, busque no álcool o «bienaventurado albergue a cualquier hora» (HV: 146) de que falou Góngora, para esquecer a miséria terrestre do homem:

Teria Gasparoto entrado no céu? Um céu onde não haveria gangrena, nem pus, nem fedor de pus. (...) Uma náusea sem limites, uma ânsia de vômito, um desejo enorme de esquecer o cheiro de pus, de sal, de urina, da cetina adocicada, do suor e do vinho azedo que regurgitava na boca. (HV: 64-65)

Se o padre nauseado anseia, no final da história, por um pouco de água fresca, para Sérgio da Costa Franco, amador de quase todas as marcas do vinho, a água não se sai muito bem na comparação com o vinho. Em «Água e vinho», ele denuncia a contaminação da água potável na atualidade, alegando que enquanto o vinho se aperfeiçoa cada vez mais em suas qualidades e variedades, a água deteriora dia a dia. Assim, lembrando o dito francês de que água deve ser usada apenas para se banhar, conclui para si próprio que ela vai «envenená-lo só no banho ou tomada ocasionalmente em dia de muita sede». (HV: 158)

Os franceses estão no centro de atenção também de Sergio Jockymann em «Negócio seguinte, tchô.», texto que traz uma comparação divertida entre a cultura do vinho francesa e a brasileira. Por meio do monólogo de um comerciante brasileiro, durante um jantar com um conterrâneo e um francês, é apresentada uma série de «barbaridades» que ele cometeu em decorrência de sua ignorância no assunto da etiqueta do vinho. A sua narração leva o hóspede francês à gradual perda de consciência:

Mas, sabe, tchô, fiquei louco pelo vinho Marjaus. Bebi cinco garrafas. Tchô, o francês... Deve ser estômago, viu? Tu precisava ver as porcaria que eles come por lá. (...) Só ganhei no vinho, porque nos queijo, Deus me livre! Tinha uns tal de calmaberto, rochaforte e não sei o que mais, que não dava pra aguentar na mesma sala. Tudo podre, tchô. Tive que jogar tudo fora. Madona, olha o francês. Pensei que ele ia cair, tchô. (...) Descobri que esse não sei o que Lafite só vai bem com salsichão. Eh, tchô, olha o francês! Ele tinha escorregado para baixo da mesa sem um gemido. (HV: 163-164)

\footnotetext{
4 Uma idéia parecida encontra-se também no poema «Das preferências», de Mário Quintana, que fala de uma maior «firmeza» do corpo: «O espírito é variável como o vento... / Mais coerente é o corpo, e mais discreto. / Mudaste muita vez de pensamento, / Mas nunca de teu vinho predileto...» (HV: 105)
} 
O ato de beber vinho tem uma imprescindível função social: não apenas aproxima as pessoas, ajudando a criar uma atmosfera de amizade e estimulando afetividade, humor e alegria, mas também dá ao indivíduo a sensação de pertencer a uma comunidade. No texto de Cyro Martins, que representa o capítulo final do romance «Um menino vai para o colégio», o vinho torna-se símbolo da entrada no mundo dos adultos. É através das sensações proporcionadas pela degustação do vinho Clarete, acompanhado com um maço de cigarros, que o jovem protagonista, sentado no restaurante, vive sua iniciação nos prazeres até então desconhecidos:

Chupa a fumaça, medroso. Depois do vinho, não era tão mau o gosto estranho. Que lástima não poder prolongar aquilo indefinidamente! O silêncio, a penumbra, a delicadeza do garçom, tudo lhe comunicava uma sensação esquisita de alívio, de conforto, de vida elegante. (HV: 35)

A narrativa humorística de Moacyr Scliar apresenta o outro lado da moeda, sendo conduzida da perspectiva de alguém que não bebe álcool e por isso mesmo é, se não excluído da companhia das pessoas «normais», pelo menos olhado com muita desconfiança. Embora descreva uma série de cenas divertidas, o texto no fundo questiona um certo automatismo e massificação que o consumo de bebidas alcoólicas adquiriu na sociedade contemporânea, sendo expressão do estilo de vida «chique» e não do gosto pessoal:

Não beber, numa sociedade que faz do álcool um meio de amável confraternização? Não beber, no país do Proálcool? Incrível! Incrível, mas tristemente verdadeiro. (...) A esta altura os circunstantes já me olham como se eu fosse uma criatura exótica, um homenzinho verde de Marte, ou, no mínimo, o sacerdote de uma seita de fanáticos dos píncaros do Himalaia. (...) Se as pessoas não bebem, deve ser por algo muito complicado. Inconfesável, provavelmente. A hipótese de doença venérea passa a ser mencionada pelos cantos. Minha mulher é até encarada com piedade. (HV: 116-117)

Também o protagonista da história «O expert», de Luis Fernando Verissimo, é abstêmio, apesar de ser reconhecido mundialmente como um grande especialista em vinhos. Ele adquiriu seu conhecimento enológico durante a estada na prisão, quando teve acesso a um único livro, uma enciclopédia de vinhos, que o ajudou a sobreviver. Neste caso, não é o gosto do vinho mas a palavra sobre o vinho que proporciona prazer - o prazer da leitura que simultaneamente consola e liberta o espírito.

\section{Textos de poesia}

No que se refere aos poemas do livro, predominantemente líricos, eles já por sua «natureza a-narrativa» (Moisés 1997: 157) não criam enredo ou ação organizada pela causalidade lógica, mas tratam o assunto do vinho de uma maneira a-temporal, imediata e pessoal. Se entra neles a História, apresenta-se sempre filtrada pela consciência do sujeito lírico que converte passado, presente e futuro em uma unidade compacta, fora das dimensões reais do tempo cronológico. ${ }^{5}$ Nos textos poéticos, os autores abordam vários conceitos associados ao vinho, projetam sentimentos e emoções para com a região vinícola e seu povo, suscitam imagens do cotidiano da comunidade, recorrem às lembranças da infância. Por exemplo, em «Cabernet», Luiz Sperb Lemos faz homenagem ao pai falecido pela decisão de perpetuar seu ritual de beber esta casta de vinho: «Meu pai tomava vinho Cabernet às refeições. / Agora não pode mais fazê-lo. / Hoje eu o faço por ele. / (...) / Perdoa-me meu pai morto que vive em mim / se não o faço exatamente como tu o fazias». (HV: 77)

\footnotetext{
5 Ver o capítulo «O tempo», Moisés 1997: 146-152.
} 
Não é de surpreender que o último poema do livro, «Caxias», de Vargas Netto, represente uma expressão explícita do amor à terra natal, que aliás brota de quase todos os textos: «Eu amo Caxias, / por todas as emoções que ela me deu.../ (...) / Eu amo Caxias, principalmente... / pela coisa melhor, que não contei...» (HV: 167-168)

É nas composições poéticas onde deparamos, frequentemente, com a descrição da paisagem e das condições naturais das regiões vinícolas, lemos sobre as cores e os sabores das uvas, ou sobre as qualidades gustativas e aromáticas de vinhos. É lá onde conhecemos até os passos do complexo processo da produção do vinho. Por exemplo, o conjunto de poemas intitulado «Decameron vinífero», de Oscar Bertholdo, oferece uma descrição das etapas desse ciclo que iniciam com a ressurreição das vinhas na primavera, passam pelos trabalhos de poda, enxertio ou pulverização, e chegam até o período da vindima, seguida por esmagamento, fermentação e envelhecimento da bebida nas adegas. A última composição, «Bríndisi», capta a atmosfera festiva no ponto final do processo - no momento da degustação do vinho: «Meu poema aplaude / o que é puro assim assim / vamos beber cantando / chiribibim bim bim...» (HV: 141)

O cultivo da uva exige não apenas conhecimento, passado de geração em geração, mas também o amor e um tratamento delicado. A este fato alude Itálico Marcon em «Explicação da uva»: «A uva, essencialmente, / reclama dedicação: / o amanho da terra / para uma boa brotação, / o cultivo dos pés / das múltiplas parreiras, / e a poda dos seus ramos / com cuidados de mulher». (HV: 51) A dedicação é mais tarde devolvida na qualidade do vinho que, porém, ao homem pode proporcionar tanto sublimação quanto perdição, como já advertiu Paulo Mendes Campos (ver acima): «Exigindo todo o amor / de quem a trata, / de quem a colhe, / é uva de renome, que, além de fartar, também sabe matar / a vida do homem». (Itálico Marcon, «Uva melhor», HV: 49-50)

Vários poemas destacam o fato de que por trás das sensações de alegria, leveza e prazeres etéreos, que o vinho pode oferecer, se esconde um duro trabalho físico: «O bom vinho sabe a fogo, / mas também a suor, / à terra machucada, / espremida em suas entranhas.» (Itálico Marcon, «Louvação do vinho», HV: 45) O resultado deste trabalho nunca é seguro, estando à mercê de uma série de fatores. Para se fazer um vinho de qualidade, é preciso haver uma feliz confluência da ação dos quatro elementos da natureza, por um lado, e do esforço unido dos homens, por outro:

O vento faz seu caminho / onde o sol desemboca o mar, / onde a terra tarja o vinho, / onde a noite é seu lagar. // (...) O homem sempre é mais forte / se a outro homem se aliar; o arado faz seu caminho / no seu tempo de cavar. // (...) Por mais que a morte desfaça / há um homem sempre a lutar; o vento faz seu caminho por dentro, no seu pomar. (Carlos Nejar, «O campeador e o vento 1, 2», HV: 25-26)

Assim, a prosperidade atual das zonas vinícolas no sul do país ${ }^{6}$ deve-se à luta com duras condições de vida dos antepassados, que conseguiram construir uma espécie da «Itália nos trópicos», ${ }^{7}$ transformando completamente o caráter original da região: «Da cepa

\footnotetext{
6 «Com uma economia equilibrada entre a indústria e a agropecuária e sem grandes desajustes sociais, o Rio Grande do Sul é o estado brasileiro com o melhor Índice de Desenvolvimento Humano (IDH). (...) A região apresenta os melhores indicadores de mortalidade infantil, educação e saúde do país e possui a segunda renda per capita, inferior apenas à do Sudeste.» (Almanaque Abril - Brasil 2003: 406, 347)

7 «Os primeiros imigrantes italianos que vieram para o Brasil chegaram ao país duas décadas antes do contingente que iria penar nos cafezais do Oeste Paulista. Embora menos cruel, sua saga não deixaria de ser amarga e áspera. Ao contrário de seus sucessores, porém, esses primeiros 'colonos' seriam, por uma série de circunstâncias, capazes de construir quase seu próprio 'país' nas verdejantes serras do Brasil meridional.» (Bueno 2003: 267)
} 
dessas matrizes / de aspecto próspero e lindo, / outras vergônteas, felizes, / aqui e ali vão surgindo. // (...) Multiplicam-se os vinhedos, / entre restos de pinhais, / porque pinhais propriamente, / meu Deus, não existem mais.» (Mansueto Bernardi, «Caminhos coloniais», HV: 82)

A expressão mais explícita desta consciência histórica apresenta-se no poema «Festa da uva», ${ }^{8}$ de Olmiro de Azevedo:

- até nas lágrimas dos colonos velhos, / pioneiros da civilização, / derradeiros bandeirantes, / remanescentes da imigração / que deram à terra do Rio Grande / suor, e sangue, e vida, e amor, / (...) / há a emoção / do patriarca em frente à prole, / a abençoar a terra / que repetiu, num sonho, / o milagre bíblico / da multiplicação dos pães... (HV: 124-125)

O poema volta até os primórdios da história da colonização italiana da região, ${ }^{9}$ celebrando o sacrifício e esforço ${ }^{10}$ dos primeiros imigrantes, na maioria camponeses pobres vindos do norte da Itália. Incapazes de sobreviver no país de origem, ${ }^{11}$ deixaram-se atrair pelas velhas imagens de um país «afável, gentil, onde tudo se multiplicava à larga», ${ }^{12}$ que tiveram a sua revivescência na Europa no séc. XIX, em grande parte graças à promoção dos agenciadores de mão-de-obra para o Brasil. O fato de que muitos dos imigrantes encontraram na América condições de vida ainda mais desfavoráveis, conhecido de inúmeros documentos históricos, é registado também na poesia popular. Comparemos, por exemplo, as letras das duas canções que circulavam entre os italianos em diferentes momentos históricos - uma antes da partida para a terra prometida, outra depois de terem conhecido a realidade:

Vamos para a América / Naquele belo Brasil / Aqui ficam os nosso ricos senhores / A trabalhar a terra com a enxada ... ${ }^{13}$

Na América onde chegamos / Não encontramos nem palha nem feno / Dormíamos no chão ao sereno / Como as bestas irracionais / E com o engenho dos nossos italianos / E o esforço de nossos paisanos / Com o passar dos anos / Construímos países e arraiais. ${ }^{14}$

Os italianos representaram sem dúvida uma importante contribuição para a criação daquele caldeirão multirracial que é o Brasil hoje em dia. Movidos pelo sonho de recons-

O título refere-se a uma festa tradicional em Caxias do Sul.

9 «O ciclo da colonização italiana no Rio Grande do Sul iniciou-se em 1875. Pequenos agricultores, procedentes em maioria do Tirol e do Vêneto, se estabeleceram em colônias na serra gaúcha, sendo Caxias do Sul a mais importante delas. (...) Supostamente, os colonos teriam vantagens, como terras, sementes e equipamentos. Mesmo que, na prática, tais banefícios raramente tenham sido concedidos, a verdade é que o Império - baseado na crença racista de que os trabalhadores europeus eram superiores - proporcionou aos recém-chegados o que sistematicamente negara a seus demais súditos: terra para o cultivo.» (Bueno 2003: 268)

${ }_{10}$ Os colonos italianos eram conhecidos por sua mentalidade trabalhadora: «Por sua vez, a maior parte das casas de italianos tem suas portas fechadas, aqui ou ali uma camponesa que lava roupa, uma velha ou um velho rodeado de crianças. Os italianos de dez anos para cima, homens ou mulheres, estão todos no campo a trabalhar.» Lomonaco, Alfonso (1900), Al Brasile, Milão: Tip. Vallardi, 73. (Cit. em Novais - Sevcenko 2004: 275)

11 «A maioria dos imigrantes que chegaram a São Paulo, até os primeiros anos do século XX, era formada por trabalhadores do campo ou pequenos proprietários rurais do norte da Itália - das regiões do Vêneto e da Lombardia sobretudo -, sem condições de sobreviver com o cultivo de seu pedaço de terra.» (Fausto 1999: 207) Ao analisar as causas da expulsão do Vêneto, região que cooperou com $30 \%$ do total de imigrantes italianos para o Brasil, Emilio Franzina diz que os observadores da época extasiavam-se pelo fato de que no Vêneto «podiase morrer de inanição e que a única alimentação da classe rural não passava de polenta, uma vez que a carne de vaca era 'um mito' e o pão de farinha de trigo inacessível pelo seu alto preço.» FranzinA, Emilio (1976), La Grande Emigrazione, Veneza: Marsilio Editori, 191. (Cit. em Novais Sevcenko 2004: 222-223)

12 Ibid., 219.

${ }^{13}$ Cit. ibid. 218.

${ }_{14}$ Canção popular dos imigrantes italianos. (Cit. em Bueno 2003: 266). 
truir no novo continente o Velho Mundo, criaram uma comunidade que até hoje em dia conserva a herança italiana nos costumes, na culinária ou no dialeto: «Nascidas no Brasil, / as mulheres que cantam / e erguem no ar cachos de uvas, / louras e morenas, / têm uma linguagem estranha / em que se mesclam / o sabor peninsular da terra de d'Annunzio / e o modismo regional de nossa gente». (HV: 122) A esta realidade linguística refere-se também Ernani Fornari no poema «Domingo lírico»: «De guarda-sol aberto, e alma aberta ao sol, / vão grupos cantando uma toada dolente / trazida pelos pais da pátria distante: 'E la violetta... la và... la và / la và - la vààààà...'» (HV: 41)

Em «Festa da uva» encontramos, porém, também alusão indireta a um aspecto obscuro da história da colonização da região: ao extermínio e desalojamento forçado dos povos nativos: ${ }^{15}$ «E até nas lágrimas dos colonos velhos / que plantaram as primeiras casas / e viram rolar as primeiras árvores / num gemido longo, / dentro da mata que desapareceu, / afugentando os bugres nus / e o uivo dos felinos». (HV: 124) Embora o autor se abstenha de fazer mais comentários a respeito da relação entre colonos e indígenas, do emprego da expressão 'bugre' - que, além de se referir a uma tribo indígena no Rio Grande do Sul, ${ }^{16}$ pode guardar também uma forte conotação pejorativa ${ }^{17}$ - fica evidente a superioridade e o desprezo na atitude do branco perante o nativo. ${ }^{18}$

Nos poemas fala-se também sobre a relação do vinho com a música, que sempre esteve profundamente enraizada no estilo de vida das comunidades da região: «Os carros vão passando / pejados de uvas e de mulheres que cantam. / (...) / A cidade acordou toda na rua, / para o Cântico do Sol / na velha praça.» (Olmiro de Azevedo, «Festa da uva», HV: 122-123); «Dentro de cada cantina / chiribibim chiribibim / um coreto de música / não se esquece de mim.» (Oscar Bertholdo, «Decameron vinífero, 10», HV: 141) Uma expressão lúdica desta relação apresenta-se na composição poética intitulada «Vinha musical», de Ernani Fornari, construída por uma série de metáforas baseadas na semelhança visual entre os elementos dos dois campos: a encosta da montanha coberta das fileiras de vides é equiparada com a pauta musical, as vinhas com as partituras, os cachos das uvas com as notas (as brancas são as semibreves, as negras são as semifusas) sendo, finalmente, a própria montanha associada a um Conservatório e o vinhateiro ao professor.

A religião, tal como a música, fez sempre parte indissociável do dia-a-dia dos habitantes da região que trouxeram para o Novo Mundo a sua fé e os rituais religiosos. A este fato alude o poema «Domingo lírico», de Ernani Fornari, que traz imagens do «dia das purificações» em uma cidade colonial, imagens que giram em torno de duas constantes

\footnotetext{
15 «Os colonos italianos foram levados para o Sul, a fim de ocupar terras devolutas - amplas regiões da qual grupos indígenas, em especial os Kaingang, haviam sido violentamente desalojados pelos chamados 'bugreiros' (caçadores/matadores de indígenas, eventualmente contratados pelas próprias empresas encarregadas de instalar os imigrantes). (...) Depois da chegada de alemães e italianos, a 'nação gaúcha' ficaria reduzida ao pampa, enquanto, na serra, brotava um novo Brasil - que logo se revelaria refratório e exclusivista.» Ibid., 267. «Mesmo não participando diretamente das matanças, os imigrantes foram omissos na questão indígena...» (Novais Sevcenko 2004: 277)

16 Ibid., 276

${ }_{17}$ Trata-se de uma denominação pejorativa e obsoleta, «dada a indígenas de diversos grupos do Brasil, por serem considerados sodomitas pelos europeus. (...) o emprego do vocábulo para denotar o indígena liga-se à idéia de 'inculto, selvático, não cristão'. » (Dicionário Houaiss da Língua Portuguesa 2004: 526)

${ }_{18}$ Os documentos da época confirmam o fato de que «os indígenas nunca foram considerados vizinhos ou proprietários das terras onde se encontravam. Assim, o que parece é sempre a figura do índio sanguinário, atacando as plantações, raptando as mulheres e matando as crianças.» (Novais Sevcenko 2004: 275)
} 
- o vinho e a igreja: «depois da missa, / os colonos vão para as vendas da vila / quebrar o jejum... / / Vem de lá dentro a cantoria em coro / dos que deixaram na igreja / todos os pecados que entristecem: / / 'Viva il vino spumeggiante / nel bicchiere scintillante...'» (HV: 40) A terra e a religião, fontes principais do alimento material e espiritual do camponês, continuam a representar dois pilares de sua existência, tal como representavam para seus avós, ${ }^{19}$ que decidiram fugir à miséria e à proletarização nas cidades européias para poderem manter seu estilo de vida, baseado no apego à terra. ${ }^{20}$ Foi em grande parte graças à lavoura e aos rituais religiosos que a colônia conseguiu manter-se unida e sobreviver como comunidade. ${ }^{21}$

Estas duas constantes, o vinho e a igreja, são destacadas também nos poemas de Mansueto Bernardi, concretamente na evocação da paisagem da região, das cenas domésticas e dos santos populares:

Ora, em lugar dos pinheiros / e dos cedros centenários, / se elevam flechas e cruzes / de igrejas e campanários. («Caminhos coloniais»); Avultam na toalha colorida, / entre a fruta e a verdura, o vinho e o pão. / (...) / tudo, na essência dessa humilde ceia, / tem um sabor sacral de comunhão. («A ceia do agricultor»); Mas, entre oráculos tantos, / que descortina o viageiro, / é o frade casamenteiro, / é Santo Antônio o campeão. («Cemitério dos imigrantes») (HV: 81-85)

É sobretudo o período da vindima que é celebrado como uma revelação, como um momento epifânico na comunidade da colônia, no qual o vinho e a fé se encontram em uma união indissociável: «A praça da capela / festeja a epifania, / as rezas santificam / o suor de tanto dia. / / (...) / O sino da capela / anuncia a liturgia / de milhões e milhões / de quilos de uva.» (Oscar Bertholdo, «Decameron vinífero, 6», HV: 136)

A função social do vinho, mencionada já na parte dedicada à prosa, é também tematizada no curto poema de Mário Quintana. O poeta observa que o vinho, por um lado, cria uma atmosfera de intimidade, simpatia e camaradagem entre as pessoas, por outro é a amizade que torna o consumo do vinho ainda mais agradável: «Por mais raro que seja, ou mais antigo, / Só um vinho é deveras excelente: / Aquele que tu bebes calmamente / Com o teu mais velho e silencioso amigo.» («Do sabor», HV: 103)

Contudo, o conceito com o qual o vinho costuma ser mais relacionado é o amor. O vinho e o Eros andam de mãos dadas desde o nascimento desta bebida dionisíaca, que proporciona alimento simultaneamente ao corpo e ao espírito. No nosso livro, a ligação do vinho ao sentimento amoroso e desejo erótico aparece sobretudo em textos poéticos. O relaxamento das tensões quotidianas, a excitação dos sentidos e a libertação dos anseios íntimos, que o álcool proporciona, tornam-se motivos recorrentes em muitas composições. Logo nos primeiros poemas, de Armindo Trevisan, o vinho associa-se ao êxtase

\footnotetext{
19 Já na Itália, o cotidiano dos camponeses que mais tarde emigraram para o Brasil «transcorria entre o trabalho e a igreja. (...) Ainda que miseráveis, apáticos para com a política, muitos extremamente religiosos, como os poloneses ou, na Itália, os vênetos, para esses homens e mulheres alguns valores do mundo rural permaneciam inabaláveis. O amor à terra era sem dúvida o maior deles, era o fulcro de suas existências, e toda a ordenação destas estava voltada para a manutenção de seu pedaço de terra.» Ibid., 228-229.

20 Ibid., 230.

21 «A possibilidade de se praticar a religião foi uma outra esfera a ser conquistada pelos imigrantes. (...)'A paróquia era o seu mundo, a única instituição com a qual estavam mais familiarizados, e de cuja vida participavam. [...] Ali ele[s] era[m] alguém. Fora do âmbito familiar a paróquia era o único grupo social organizado ao qual o camponês pertencia.' » Ibid., 261-262.
} 
erótico, sendo este captado primeiro da perspectiva feminina, depois masculina e, por fim, pelo sujeito plural:

Nasci dentro de uma boda, / Numa boda me criei, / casei-me, límpida e toda, / com aquele que eu amei. / / Velou-me o rosto o tecido / da carne que lhe entreguei, / deu-me um vinho apetecido / com que me ruborizei. («Canto da esfinge»); Mas tu / enquanto a carne te bebe / ... / libertas / com o desmoronar / das vespas / teu vinho / de fêmea. («Celebração»); ...morreremos / embriagados / de uma luz / que nunca / aqueceu / nossas veias. («Salmo dos bêbados») (HV: 15-17)

Em «Vindima» (Augusto Meyer), é durante o ato de colher uvas que o sujeito lírico evoca imagens da mulher desejada: «és uma vinha selvagem que oferece / cachos de beijos para a minha fome!» (HV: 21) Na mesma situação descreve a beleza feminina Olmiro de Azevedo: «Que doçura singular têm essas uvas, / quando as colhem, assim, colonitas ariscas, / de pernas nuas, cantarolando...» («Pastoral», HV: 121)

Tendo-nos debruçado ao longo deste trabalho sobre os modos de tratamento do tema do vinho em trinta e quatro textos de prosa e poesia, deparamos com uma surpreendente variedade de perspectivas, enfoques e atitudes que seus autores adotaram. Observamos que nas narrativas prevalece o tom humorístico, com o qual são tratadas questões como a origem do vinho, as diferenças entre as culturas do vinho, a fraca natureza do homem perante as tentações do álcool ou a discriminação social dos que não bebem. Os textos poéticos, por sua vez, representam uma expressão do amor pela região vinícola e da consciência de sua tradição histórica, ou discutem a relação do vinho com vários conceitos como música, alegria, religião, amizade ou amor. Em ambos os gêneros salientase a imagem do vinho como uma arma poderosa contra a efemeridade da existência, associada ao tema do carpe diem. A presente riqueza na abordagem da matéria do vinho é a prova da profunda inspiração que esta bebida continua a exercer sobre o ser humano, como já há tempos afirmava um hábil pintor dos prazeres da vida terrestre: «Enchamos os copos, pois o vinho nos inspira, / e nos inflama / com coragem, amor e alegria. / Em mulheres e vinho deveríamos a vida empregar. / Há algo na terra que seja mais desejável?» (John Gay, Ópera do Mendigo)

\section{Bibliografia}

Almanaque Abril - Brasil (2003), São Paulo: Ed. Abril.

BuEno, Eduardo (2003), Brasil: uma História, São Paulo: Ática.

Dicionário Houaiss da Lingua Portuguesa (2004), Rio de Janeiro: Editora Objetiva.

DuARTE, Elizabeth Machado - GoÉs, Maria das Graças Tavares (org.) (1997), Textos do Brasil, Julho / Setembro, ano I - n³, Brasília: Ministério das Relações Exteriores.

Fausto, Boris (1999), História do Brasil, São Paulo: Edusp.

Histórias de Vinho (1980), Porto Alegre: L\&PM Editores.

MoIsés, Massaud (1997), A Criação Literária: Poesia, 13ª ed., São Paulo: Cultrix.

MoIsés, Massaud (1995), A Literatura Brasileira Através dos Textos, 20a ed., São Paulo: Cultrix. 
Novais, Fernando A. (coord. geral) - SEvCENKo, Nicolau (org. do vol.) (2004), História da Vida Privada no Brasil, vol. 3, São Paulo: Companhia das Letras.

\author{
Zuzana Burianová \\ Katedra romanistiky \\ Filozofická fakulta \\ Univerzita Palackého v Olomouci \\ Křížkovského 10 \\ 77180 Olomouc \\ República Checa \\ zuzana.burianova@upol.cz
}

